\title{
Customer-Specific Strategies Customer retention: A usage segmentation and customer value approach
}

Received (in revised form): 19th November, 2001

\section{Art Weinstein PhD}

is Professor of Marketing in the Wayne Huizenga Graduate School of Business and Entrepreneurship at Nova Southeastern University, Fort Lauderdale, Florida. He teaches graduate courses in customer value, international marketing, managerial marketing and research, and market segmentation. He has consulted for Bayer, Hewlett-Packard, Intel, Motorola, Novartis, and many other organisations. Dr Weinstein is the author of three books - 'Market segmentation', 'Defining your market', and 'Designing and delivering superior customer value', and more than 50 scholarly articles/papers on marketing strategy.

\begin{abstract}
This paper discusses how companies should develop a customer retention focus and initiatives to maximise long-term customer value. Specifically, it examines the importance of customer retention; conceptualises an integrated customer value/retention model; and explains how usage segmentation can assist in relationship-building, retention strategy and profit planning. A brief case history of Fast Industries, a specialty plastics manufacturer, illustrates these ideas in practice. Implications for marketers and customer value managers are offered and research directions for scholars working in retention marketing are identified.
\end{abstract}

Art Weinstein

Nova Southeastern University, Huizenga School, 3100 SW 9th Avenue, Fort Lauderdale, FL 33315 USA.

Tel: 954-262-5097; Fax: 954-262-3965; e-mail: art@huizenga.nova. edu
Custom Research, Inc. (CRI), a Minneapolis-based (USA) marketing research firm was able to cut its customer base in half yet triple its revenues and double its profits over a ten-year period ending in 1998. This was accomplished by practising individualised 'surprise and delight' marketing for three dozen high-volume/high-margin clients (CRI's core partners), hand-picking and growing profitable new accounts (averaging \$200,000 annually), and systematically eliminating more than 100 low-volume/low-margin customers. ${ }^{1}$

\section{WHY FOCUS ON CUSTOMER RETENTION?}

Most companies spend a majority of their time, energy and resources chasing new business. While it is important to find new customers to replace lost business, grow the enterprise and expand into new markets, this goal should be secondary in importance to the main objective - keeping customers and enhancing customer relationships. For example, in France, customer retention is critical in the mobile phone market; operators have large customer acquisition expenditures and lose more than 30 per cent of their subscribers annually. ${ }^{2}$ The profitability of customer retention strategies can be determined by industry retention rates, usage segmentation and creating and measuring long-term customer value. ${ }^{3}$

In an analysis of switching behaviour 
in service industries, Keaveney found that service-oriented factors such as core service problems, service encounter failures, inconvenience, response to failed service and other issues accounted for about 70 per cent of the reasons why customers defect (pricing strategies only accounted for 17 per cent of the switching behaviour). ${ }^{4}$ Once marketers realise that customers leave organisations primarily due to service reasons, these issues become highly controllable from the firm's perspective.

Frederick Reichheld, of Bain \& Company, is a leading consultant on loyalty management. In his book,' The loyalty effect', he builds a strong case for emphasising employee retention and customer retention in business. Service companies must retain the best personnel to win and keep good customers - the average company loses about half of its employees in four years. He notes that it is impossible to build a loyal bank of customers without a loyal employee base. Reichheld also shares these important statistics on the significance of customer retention: ${ }^{5}$

- on average, US corporations lose half of their customers in five years

- a typical company has a customer defection rate of $10-30$ per cent per year

- raising the customer retention rate by 5 per cent can increase the value of an average customer (lifetime profits) by 25-100 per cent

- Lexus has repurchase rates more than 20 per cent higher than Infiniti. While Lexus only accounts for 3 per cent of Toyota's sales, it contributes 30 per cent toward their profits

- State Farm determined that a 1 per cent increase in customer retention will increase its capital surplus by more than $\$ 1$ bn over time.
Later, Reichheld advised firms to 'be picky' because a 'truly humble company knows it can satisfy only certain customers, and it goes all out to keep them happy'. Vanguard was cited as an exemplary organisation in this regard. Targeting long-term investors rather than day traders, Vanguard's service:expense ratio (0.3 per cent) was one-quarter of the industry average (1.2 per cent). ${ }^{6}$

While a study by Marketing Metrics, a New Jersey (USA) firm, notes that corporations spent 53 per cent of their budget on customer retention, there is still concern that most effort is spent on wooing new customers, or the great 'one-night-stand'. A vice president at that firm urged marketers to look at this figure with scepticism. He noted that the definition of retention marketing is so broad that databases, satisfaction surveys and couponing can qualify as retention activities (often such initiatives do not target existing high-value customers); compensation and promotions are generally based on demonstrating short-term profits (transaction business) at the expense of longer-term paybacks; and retention is viewed by many companies as the 'fad of the week'. ${ }^{7}$ In reality, 80 per cent or more of marketing budgets are often earmarked for getting new business (or less than 20 per cent for keeping customers). A preferable approach may be to invest at least 75 per cent of a company's marketing budget on relationship marketing activities and customer retention strategies.

Conventional wisdom suggests that it costs at least five times more to get a new customer than keep an existing one. Some other 'well accepted beliefs' regarding customer relationship management are that companies should:

- treat individual customers as assets (portfolio management techniques can be useful in this context) 
Table 1 Usage segmentation categorisations

Heavy, medium, light, former and non-users (A,B,C,D,X)

Heavy half segmentation ( $80 / 20$ rule)

Users versus non-users

Competitive users

Loyal (degree) versus non-loyal customers

Product/service applications by user group

Adopter categories - innovators, followers, laggards, lead users

Geographic comparisons - customer penetration indices, growth

- create valid estimates of customer lifetime value

- be willing to fire unprofitable customers. $^{8}$

Philip Kotler, the internationally renowned professor at Northwestern University, states that the key to customer retention is customer satisfaction. He notes that satisfied customers:

— stay loyal longer

- talk favourably about the organisation

- pay less attention to the competition

- are less price sensitive

- offer service ideas to the organisation

- and cost less to serve than new customers. ${ }^{9}$

\section{USAGE ANALYSIS AND CUSTOMER RETENTION}

Segmenting markets by consumption patterns can be quite insightful for understanding the customer mix. Land's

End and LL Bean use 'customer purchase patterns to compute the probability of purchase for each of the merchandise lines. Armed with this information, these firms send the customer only those catalogues for which the calculated purchase probability exceeds a threshold value. ${ }^{10}$

Differentiated marketing strategies are needed for various user groups first-time users, repeat customers, heavy users and former users. By classifying customer accounts based on usage frequency and variety, companies can develop effective and profitable strategies for retaining and upgrading customers. As Table 1 shows, there are many highly informative, low-cost applications of usage analysis that should be considered by management.

For example, a hotel may grade customers based on the number of rooms booked annually. The key accounts are A1 users - these are large organisations that reserve thousands of room nights and conference facilities. A2 customers also book a high volume of rooms without the conference arrangements. A third category of heavy users is the A3 account - this is a solid, loyal customer that generates hundreds of room nights, annually. Four descending usage levels of $\mathrm{B}$ customers (B1 to B4) are considered medium users. Finally, five types of $\mathrm{C}$ accounts (C1 to C5) represent light users. The C5 guest may only visit the hotel once a year.

By classifying customers into usage categories, management can design appropriate strategies for each market segment. The objective is to move customers up the ladder, where possible. The implication of usage analysis is that all customers are not equal — some (the heavy users) are clearly more valuable than other categories. For example, McDonald's Corporation actively targets 'super-heavy' users. These customers are typically male, aged 18 to 34 and eat 
there three to five times a week, accounting for 77 per cent of its sales. ${ }^{11}$

In business and professional service markets, the best customers may be identified as key accounts based on customer ranking (eg the 100 most important customers), minimum sales volume level (eg $\$ 1 \mathrm{~m}$ in annual business) or market share (eg an annual account exceeds 1 per cent of the total business). The Pareto Principle or $80 / 20$ rule is insightful in this context. In a typical business approximately 80 per cent of sales come from about 20 per cent of customers and generally, about 80 per cent of sales come from 20 per cent of the goods or services offered. It is essential to defend this core business base since heavy users (A accounts) are primary targets for key competitors. These highly profitable customers require frequent advertising, promotions, sales calls and ongoing communication efforts.

Strategy Consulting Inc.'s usage analysis revealed that 26 per cent of its business (long-term clients) accounted for 84 per cent of its profits. In addition, 22 per cent of its revenues (mergers and acquisitions) yielded 87 per cent of its profits. Operational projects (33 per cent of its revenues) were found to be a losing proposition for the company; and subsequent inquiries in this area were farmed out to specialist consultancies. ${ }^{12}$

Medium users (B customers) form the solid foundation of a business. Revenue enhancement strategies such as cross-selling or value-added services can be used to keep these customers satisfied and grow their business. Telephone calls, e-mail and occasional sales calls are suggested in order to stay in touch with this group. By knowing who the better customers are (the As and Bs) through geographic, demographic, psychographic and benefit research - a profile of 'typical users' is established. This information is very helpful in planning subsequent customer attraction/conquest marketing efforts. The marketing information system, the database, plays a pivotal role in customer analysis and decision making.

For unprofitable customers (many C accounts), the company often needs to find new ways to serve them more effectively. Technology such as ATM machines can be used in this regard. Quarterly contact through newsletters and direct mail or access options such as charge free telephone numbers and websites maintains adequate communication with low-volume users. In some cases, it is even desirable to sever the relationship with unprofitable customers.

A good understanding of customers' purchasing patterns helps firms keep customers and gain a larger share of their business. Share of customer (a customer retention measure) has supplanted market share (a customer attraction objective) as the relevant business performance dimension in many markets. Share of customer can be adapted by industry and goes by such names, among others, as share of care (healthcare), share of stomach (fast food) and share of wallet (financial services). For example, if a company is able to increase a customer's share of business from 20 per cent to 30 per cent this can have a dramatic impact on market share and profitability.

Recency, frequency and monetary value (RFM) analysis is a helpful tool in evaluating customer usage and loyalty patterns. Recency refers to the last service encounter or transaction; frequency assesses how often these customer contact/company experiences occur; and monetary value probes the amount that is spent, invested or committed by customers for the firm's products and services. A few years ago, this author purchased about $\$ 75$ worth of 


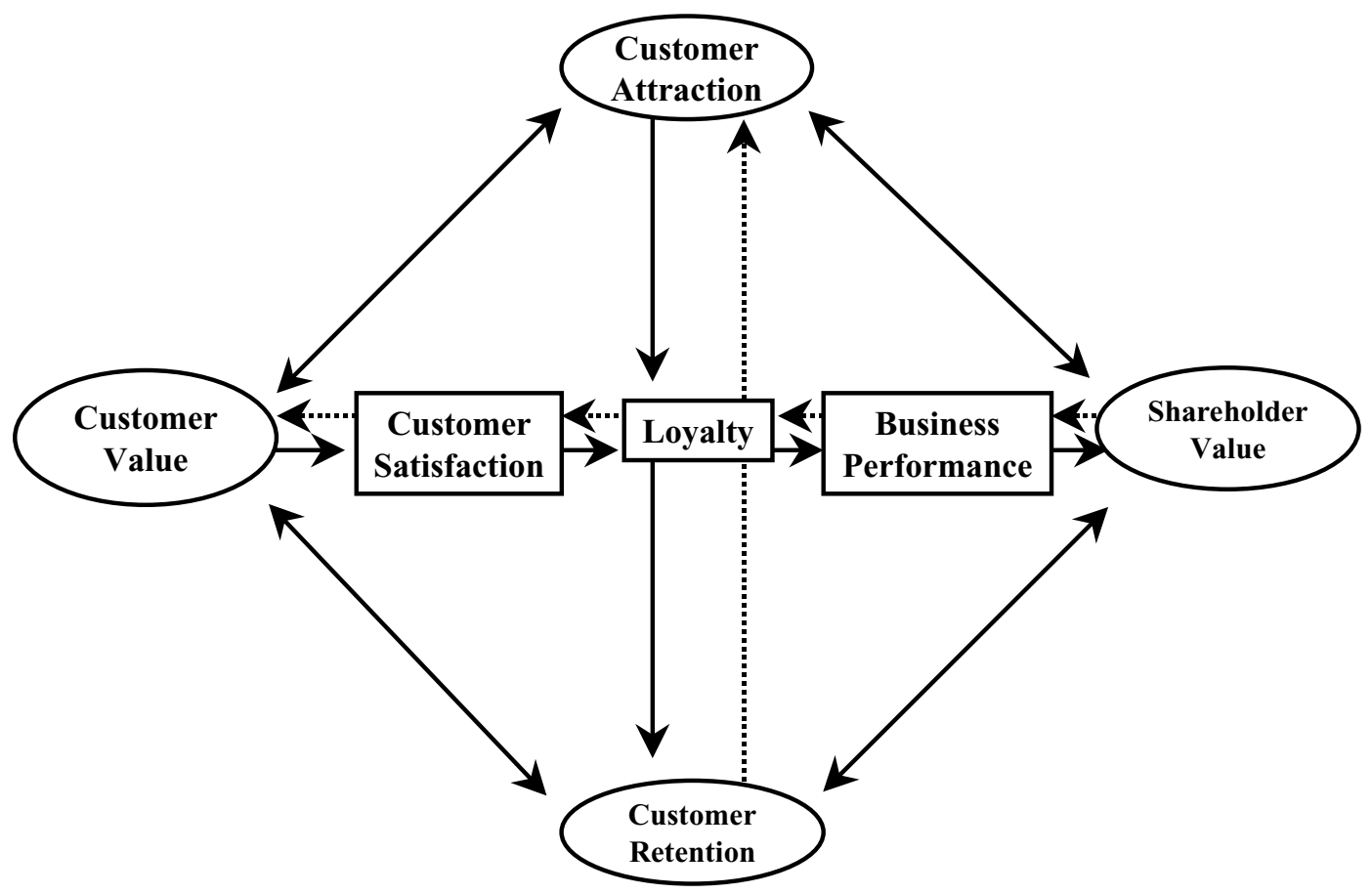

Figure 1 The Customer Retention/Value Model

brochure materials from a direct marketing firm for a one-time consulting project. This eager vendor immediately placed the author in the preferred customer category and began sending him expensive catalogues about every three weeks without any follow-up orders. RFM analysis tells us that this is not sound marketing practice since this company essentially treats all one-time triers as 'best' customers. Note that this transaction scored poorly on all the critical RFM dimensions: recency (three plus years ago); frequency (a single purchase); and monetary value (relatively low).

A more effective strategy is to classify customers via usage analysis (as previously described) and design differentiated marketing approaches for each target market. In sum, usage analysis can greatly assist customer retention activities. It is useful to think about how to 'hold' heavy users and key accounts, upgrade light and medium users, build customer loyalty, understand buying motives to meet/exceed expectations, use appropriate selling strategies for each targeted usage group, win back 'lost' customers, and learn why non-users are not responding to a value proposition.

\section{A CUSTOMER VALUE AND RETENTION MODEL}

Marketing managers know that it is critical to deliver superior value to their customers, this ensures business profitability. The proposed customer value/retention model offers a good way of conceptualising the key relationships among the core elements (eg customer satisfaction, loyalty, business performance) that create value in an organisation (see Figure 1). 


\section{The underpinnings of the model}

There has been much debate among practitioners and scholars as to what it takes to keep long-term customers and how organisations can maximise value. An integrated customer retention framework proposed by researchers in the global automobile industry lends partial support for the customer value/retention model. Johnson and colleagues explain that customer value affects customer satisfaction which in turn affects customer loyalty and ultimately customer retention. They add that loyalty increases with customer satisfaction at an increasing rate. In addition, these authors recommend that customers should be segmented by level of satisfaction prior to planning retention strategies. ${ }^{13}$ Further research in the car industry using a sample of Volkswagen customer club members in Germany found that customer satisfaction has a strong impact on customer retention, and ultimately, economic goals. ${ }^{14}$

Another German study, in the mobile cellular telecommunications market, showed empirical evidence of causal linkages from customer satisfaction to customer loyalty to customer retention. ${ }^{15}$ Similar thinking guides Hellier's model which was tested in the insurance services sector. Relevant links here include perceived value (quality is a component of this), customer satisfaction, loyalty and switching costs, and repurchase intent. Additional product and brand preference factors are reported as intervening components between satisfaction and repurchase intentions (retention). ${ }^{16}$

The SURe model states that as satisfaction $(S)$ increases, the likelihood that customers will continue to use $(U)$ a service increases as does the likelihood of the customer recommending $(R e)$ the service provider to another potential customer. Multi-industry research using regression techniques in the service sector found that a 5 per cent increase in satisfaction produces a 3 per cent increase in continued use (.6) and a 2.5 per cent increase in recommending (.5); and, a 5 per cent increase in use results in a 2 per cent increase in recommending (.4). ${ }^{17}$

Based on the above insights, a five-element approach to creating long-term customers should include components on value, satisfaction, loyalty, retention and profitability. This straightforward perspective is reflected in the proposed customer value/retention model.

\section{Discussion}

Providing superior customer value is the starting point in the horizontal customer profitability chain (Figure 1). It is based on a sound mix of quality, service and price (QSP) and the image, innovation and intangibles (the three Is). These elements enable organisations to attract and keep customers. Companies should segment markets via demographic, psychographic and usage approaches to locate new customers that find the firm's value proposition appealing.

Business firms typically use account size and industry as a basis for identifying and targeting markets. While these data are readily accessible, they often provide little insight about how specific goods and services are actually used by the customer. Therefore, product application segmentation should be considered as a value-generating tool. The marine market is a case in point. A fabric manufacturer may provide basic acrylic fabrics for power and sailboat covers as well as higher-value, custom-designed seat covers for inside the boat. ${ }^{18}$

A one-time buyer is really a try-er, rather than a customer. To move beyond the transaction stage, organisational experiences must meet or, preferably, 
exceed the buyer's expectations. Repeated incidents of high satisfaction are sought through the effective utilisation of relationship marketing strategies, leading to higher customer loyalty. According to Fredericks, Hurd and Salter, there is a significant difference between customer satisfaction and loyalty. They view the former as a largely passive customer condition while the latter requires an active or proactive relationship. ${ }^{19}$

Loyalty, in turn, (which results from the quality of the customer-company relationship) leads to improved business performance. Furthermore, the ability to retain customers results in increased market values. The vertical customer retention chain shown in Figure 1 indicates that, ideally, loyal new customers are retained for many years.

Research has shown that companies may expect loyal customers to range from about 40-75 per cent depending on the sector; loyalty, however, does not necessarily equate with exclusivity. ${ }^{20}$

Based on diversified packaged goods markets, Ehrenberg adds that 'loyal' buyers are not always truly loyal. $\mathrm{He}$ explains that repeat buying and other loyalty measures vary little and are generally in line with market share. ${ }^{21}$ Hence, he concludes that consumer behaviour can be predicted on the basis of penetration (the proportion of buyers within a designated time period) and average purchase frequency of items (the average number of times these buyers buy the item in the period). ${ }^{22}$

Feedback loops are also depicted in the customer value/retention model. Good value secures customers over the long term. Similarly, customers (both new and existing ones) want to maintain relationships with well-respected organisations that have high market values.

The customer value and marketing implications of the model are readily apparent. First, the key variables and their relationships to one another are clarified. This provides strategic guidance to management. Secondly, it stresses long-term relationships (retention) but still realises that some customer defection and attrition will occur so customer attraction must remain a priority. Thirdly, the model is interfunctional and systematic - it ties marketing objectives to the big picture, the financial situation. This is consistent with the recommendation that new marketing models should focus on customer profitability as a function of retention. ${ }^{23}$ Two telling examples of the impact of customer retention on business performance are:

- a one-tenth of a percent of the US automobile industry is worth $\$ 2.5 \mathrm{bn}^{24}$

- a 2 per cent increase in customer retention yields the same profit as a 10 per cent reduction in overhead. ${ }^{25}$

\section{CASE APPLICATION: FAST INDUSTRIES}

Fast Industries is a plastics manufacturing company located in Fort Lauderdale, Florida (USA). The company is the world's largest producer of label holders and serves leading retail store chains including Wal-Mart, Target, CVS Drugs and Michael's Crafts.

Fast Industries is undergoing a transformation from a smaller family-run manufacturing company to a more professionally structured, staffed and managed organisation. Because of the recognition that customer retention is more important than customer attraction, much effort was spent ensuring that Fast's most valuable customers perceived this change as positive and were more likely to remain a customer. Two strategic initiatives which played a central role in the new marketing strategy were the 
$80 / 20$ principle and the value proposition.

The $80 / 20$ principle was integral in determining the focus and location of Fast's most important customers. Although there are over 2,000 retail chains in the USA, due to variations in the number of stores and size of stores per chain, it was estimated that about 90 of them will purchase 90 per cent of the store fixtures components that Fast can offer. Currently, Fast does business with 30 of these retailers and for each of these key accounts delivering superior customer value is a top management priority.

Next, the value proposition was utilised to determine the exact nature of each customer's relationship with Fast. Since there are four basic providers of value to a customer (price, service, quality and image), each customer was surveyed by their respective sales representative on exactly why they do business with Fast and what aspects of value were derived from doing business with the company. Using an internally designed strategic assessment form based on the value proposition, it was found that no relationships with Fast were based on image or price alone, but that service and quality were laden with further nuances. Service to one customer might mean high levels of in-stock orders. To another it might mean ease in placing an order. To yet a third it might be constant attention from a sales representative. Quality as a criterion can be broken down into components as varied as the product's engineering and design, on-time delivery, and/or correct packing or billing of the product.

A second assessment tool was a SWOT analysis conducted at individualised and aggregate levels. Information about strengths, weaknesses, opportunities and threats was gathered from each strategic customer. An assessment of Fast's overall relationship with all accounts plus a future forecast and recommended strategy was developed. What was perhaps unique about this analysis was that it sought to describe the strategic position of business relationships in terms of the value proposition.

Through the sound application of strategic marketing principles rooted in segmentation and customer value, Fast Industries is now designing and delivering superior products/services to its most important customers. And it is working well. It is projected that this customer retention strategy will have a significant impact on profitability for the year 2001 with revenues increasing by 20 per cent and profits increasing by 25 per cent.

\section{CUSTOMER RETENTION CHALLENGES FOR MARKETERS AND RESEARCHERS}

Developing a sound and profitable customer retention strategy must be a top priority for managers to compete successfully in today's marketplace/space. Segmentation and customer value are major strategic weapons that can be used to assist in this endeavour. From a segmentation perspective, a differentiated approach to target marketing based on usage segments and key account management are two important initiatives to implement.

Marketers must realise that all customers are not the same. Clearly some users are much more important than others - these are the A customers or heavy users. This target market requires special attention via resource investment, dedicated sales/support personnel, time commitments, etc. The B customers or medium users often provide the core base for corporate accounts. Strategies for keeping and growing these customers must be designed. The $\mathrm{C}$ customers or 
light users should be served in cost-efficient programmes such as telephone call centres or websites. Key account management should be reserved for the top tier of the A customer class. Individualised marketing plans should be prepared for these clients, a relationship manager/team assigned, and one-to-one marketing should be implemented.

Customer value concepts can further illuminate the complex process of retaining customers. Conceptualisation/ operationalisation and measurement are critical challenges faced by practitioners and scholars. The definition of what constitutes customer value is often unclear. It goes well beyond price and quality and must include various service dimensions as well as perceived image, innovativeness and intangible offerings such as specialised knowledge and time savings.

While most companies spend a majority of their resources on conquest marketing (ie getting new business), the services marketing literature clearly demonstrates the value of investing in customer relationship building and retention. Customer satisfaction should be analysed for both individual service encounters/transactions and ongoing series of service opportunities. At a minimum, each service experience should be judged as to whether it exceeded, met or failed to meet customers' expectations.

Loyalty must be carefully evaluated, too. At the extreme, a company may have total or no loyalty from a customer. High, medium or low loyalty can be determined via relationship strength, switching patterns and share of the customer's business. Numerous business performance measures should also be obtained to gather strong evidence of sales and profitability (ie revenues, market share, net present value, payback periods, customer lifetime value etc.). For example, the typical costs of value-added, plastic card-based (bar coded, magnetic and smart) programmes are $0.5-1$ per cent of sales with breakeven points averaging 5-7 per cent of sales. ${ }^{26}$

Customer retention as a construct implies long-term measurement. Therefore, typical cross-sectional research is only going to be of limited value to management in gauging the effectiveness of their strategies for keeping and upgrading customers. In contrast, although it is more costly and difficult to monitor, longitudinal data are preferable for marketing information and insight purposes. Ensuring valid and reliable measures are critical in the research process. Panel/syndicated reports and sophisticated databases can be most useful in this context.

\section{SUMMARY}

Companies that deliver superior value to customers on an ongoing basis are able to keep them over the long term. This is essential for establishing a customer retention focus. By maintaining consistently high levels of customer satisfaction and loyalty, customer defection becomes less likely. This results in enhanced business performance and increases shareholder value. Usage segmentation and relationship marketing are the key strategies to obtain the desired results of retaining more customers, getting better customers, upgrading customer relationships, and using existing customers as advocates for acquiring new customers.

\section{Acknowledgement}

The author thanks Robert Fast, Vice President of Fast Industries, for contributing the case application. In addition Norapol (Paul) Chinuntdej is acknowledged for his research support in this project. This paper builds on ideas presented in 'Maximizing value through retention marketing' (Chapter 8) in the book 
'Delivering and designing superior customer value: Concepts, cases, and applications', by Art Weinstein and William C. Johnson, St. Lucie Press, Boca Raton, Florida, 1999.

\section{References}

1 Greco, S. (1998) 'Choose or lose', Customer Research Inc., December, pp. 57-66.

2 Lee, J., Lee, J. and Feick, L. (2001) 'The impact of switching costs on the customer satisfaction-loyalty link: Mobile phone service in France', Journal of Services Marketing, Vol. 15, No. 1, pp. 35-48.

3 McDougall, G. (2001) 'Customer retention strategies: When do they pay off?', Services Marketing Quarterly, Vol. 22, No. 1, pp. 39-55.

4 Keaveney, S. M. (1995) 'Customer switching behavior in services industries: An exploratory study', Journal of Marketing, Vol. 59, April, pp. 71-82.

5 Reichheld, F. F. (1996) 'The loyalty effect: The hidden force behind growth, profits, and lasting value', Harvard Business School Press, Boston, MA.

6 Reichheld, F. F. (2001) 'Lead for loyalty', Harvard Business Review, July-August, pp. 76-84.

7 Pruden, D. (1995) 'Retention marketing gains spotlight, but does reality match philosophy?', Brandweek, 6th February, p. 15.

8 Fader, P. 'Request - CRM conventional wisdom', http://www.columbia.edu/ pbp1/elmar/, cited 10th July, 2001.

9 Kotler, P. (2000) 'Marketing management: Analysis, planning, implementation, and control', 10th ed., Prentice-Hall, Englewood Cliffs, NJ.

10 Shaw, M. J, Subramaniam, C, Gek, W. T. and Weldge, M. E. (2001) 'Knowledge management and data mining for marketing', Decision Support Systems, Vol. 31, No. 1, pp. 127-137.

11 Blattberg, R. C. and Deighton, J. (1996) 'Manage marketing by the customer equity test', Harvard Business Review, July-August, pp. 136-144.

12 Koch, R. (1998) 'The 80/20 principle: the secret of achieving more with less', Currency/Doubleday, NY, pp. 65-68.

13 Johnson, M. D., Hermann, A., Huber, F. and
Gustafsson, A. (1997) 'Customer retention in the automotive industry', Gabler Publishers, Wiesbaden, Germany, p. 6.

14 Stauss, B., Chjnacki, K., Decker, A. and Hoffmann, F. (2001) 'Retention effects of a customer club', International Journal of Service Industry Management Vol. 12, No. 1, pp. 7-19.

15 Gerpott, T., Rams, W. and Schindler, A. (2001) 'Customer retention, loyalty, and satisfaction in the German mobile cellular telecommunications market', Telecommunications Policy, Vol. 25, No. 4, pp. 249-269.

16 Hellier, P. K. (1995) 'Discovering the major factors influencing customer retention in services industries', Asia Pacific Journal of Quality Management, Vol. 4, No. 2, pp. 62-65.

17 Ralston, R. W. (1996) 'Model maps out a sure path to grow in the marketplace', Marketing News, 20th May, pp. 12.

18 Anderson, J. C. and Narus, J. A. (1991) 'Partnering as a focused marketing strategy', California Management Review, Spring, pp. 95-113.

19 Fredericks, J. O., Hurd, R. R. and Salter II, J. M. (2001) 'Connecting customer loyalty to financial results', Marketing Management, Spring, pp. 26-32.

20 O'Dell, S. M. and Pajunen, J. A. (2000) 'The butterfly customer: Capturing the loyalty of today's elusive consumer', John Wiley \& Sons, Toronto.

21 Ehrenberg, A. (1997) 'Description and prescription', Journal of Advertising Research, Vol. 37, No. 6, pp. $17-22$

22 Ehrenberg, A. S. C. (1998) 'Repeat-buying: Facts, theory and applications, Griffin, London.

23 Leeflang, P. S. H. and Wittink, D. R. (2000) 'Building models for marketing decisions: Past, present, and future', International Journal of Research in Marketing, Vol. 17, pp. 105-126.

24 Waldrop, J. (1994) 'How to succeed despite slow growth', American Demographics, April, pp. 52-56.

25 Marchetti, M. (1996) 'How the CEO of Unisys creates customer value', Sales and Marketing Management, October, p. 45.

26 Wray, P. G. (1996) 'Loyalty programs strategy', http://www.loyaltymatters.com/strategy.html, cited August, 1999. 